\title{
Haplotyping, linkage mapping and expression analysis of barley genes regulated by terminal drought stress influencing seed quality
}

\author{
Sebastian Worch', Kalladan Rajesh', Vokkaliga T Harshavardhan', Christof Pietsch², Viktor Korzun², Lissy Kuntze ${ }^{3}$, \\ Andreas Börner ${ }^{1}$, Ulrich Wobus ${ }^{1}$, Marion S Röder ${ }^{1}$, Nese Sreenivasulu ${ }^{1 *}$
}

\begin{abstract}
Background: The increasingly narrow genetic background characteristic of modern crop germplasm presents a challenge for the breeding of cultivars that require adaptation to the anticipated change in climate. Thus, high priority research aims at the identification of relevant allelic variation present both in the crop itself as well as in its progenitors. This study is based on the characterization of genetic variation in barley, with a view to enhancing its response to terminal drought stress.
\end{abstract}

Results: The expression patterns of drought regulated genes were monitored during plant ontogeny, mapped and the location of these genes was incorporated into a comprehensive barley SNP linkage map. Haplotypes within a set of 17 starch biosynthesis/degradation genes were defined, and a particularly high level of haplotype variation was uncovered in the genes encoding sucrose synthase (types I and II) and starch synthase. The ability of a panel of 50 barley accessions to maintain grain starch content under terminal drought conditions was explored.

Conclusion: The linkage/expression map is an informative resource in the context of characterizing the response of barley to drought stress. The high level of haplotype variation among starch biosynthesis/degradation genes in the progenitors of cultivated barley shows that domestication and breeding have greatly eroded their allelic diversity in current elite cultivars. Prospective association analysis based on core drought-regulated genes may simplify the process of identifying favourable alleles, and help to understand the genetic basis of the response to terminal drought.

\section{Background}

Drought is one of the most serious abiotic stress factors which occur throughout the development of the plant and, if sufficiently severe and/or prolonged, results in the modification of the plant's physiology and severely limit crop productivity. Plants have evolved a range of defence and escape mechanisms [1], and these are typically mediated by multiple rather than by single genes. In barley, QTL underlying drought tolerance has been mapped to almost every chromosome [2-6]. However, little information has been gathered to date regarding the genomic location of drought-regulated genes, either

\footnotetext{
* Correspondence: srinivas@ipk-gatersleben.de

'Leibniz-Institute of Plant Genetics and Crop Plant Research (IPK),

Corrensstr.3, 06466 Gatersleben, Germany

Full list of author information is available at the end of the article
}

expressed throughout plant development or at late reproductive stages influencing seed yield and quality.

Of all the genetic marker types available, single nucleotide polymorphisms (SNPs) are the most abundant, and thus offer the greatest level of genetic resolution. They are of potential functional relevance and they are also well suited to high throughput analytical methods [7]. The representation of SNPs on the barley linkage map has grown over recent years [8-10], and in particular, a SNP-based map featuring gene sequences expressed differentially in response to various abiotic stresses has recently been developed [7]. Here we present a SNP-based genetic map of barley, specifically focussing on nucleotide variation in ESTs demonstrated to be involved in the response of barley to drought stress occurring at early vegetative stages, during anthesis and the grain filling process. 
While the productivity of the cereals has risen greatly since their domestication, in response to farmer selection and methodical breeding, there are indications that the increasing fixation of elite alleles in modern breeding germplasm is already inhibiting further genetic gain. In the face of potential climate change, these elite allele combinations may become sub-optimal and will necessitate a search for better adapted alleles among crop landraces or wild materials [11]. Population of wild barley (Hordeum vulgare ssp. Spontaneum, hereafter referred to as $H$. spontaneum) have been shown to possess favourable genetic variation for a number of agronomic traits $[12,13]$ including biotic $[14,15]$ and abiotic stress tolerance [2,16-19].

We report haplotyping data for 17 starch biosynthesis/ degradation genes demonstrating the broad diversity among $H$. spontaneum accessions and $H$. vulgare landraces but rather limited genetic variance in the current elite breeding germplasm by fixing certain haplotypes. Similar observations were made for seed starch accumulation during terminal drought for a diverse set of 50 barley accessions.

\section{Results and Discussion}

SNP discovery in sequences responding to drought stress The initial set of 613 drought-responsive ESTs (covering 20 functional categories; Additional file 1) was determined from 5 or 21 day old seedlings, flag leaves-post anthesis or developing grains. Suitable sequence information from the four parents of mapping population and the four advanced backcross (AB) population parents were obtained for 327 genes (53.3\%). The sequence reads were assembled individually for each locus. A total of 1,346 informative SNPs were dispersed through 263 of the sequences, giving a mean SNP density of 5.1 per kb (Additional file 2). The Oregon Wolfe parents were the best differentiated (627 SNPs across 181 ESTs, density 3.4 per $\mathrm{kb}$ ), which is consistent with comparisons made elsewhere between these two lines $[7,20]$. Some $30 \%$ of the loci were polymorphic between cvs. Steptoe and Morex, as noted in the previous studies for these cultivars $[10,20]$. The proportion of informative loci in cv. Brenda versus HS584 was 33\%, and between cv. Scarlett and ISR42_8 39\%. Note that a polymorphism survey based on 400 microsatellite loci showed that $46 \%$ were informative between cv. Brenda and HS584 [21], while 97 out of 220 (44\%) were polymorphic between cv. Scarlett and ISR42_8 [22].

\section{Marker development and linkage mapping}

The SNPs present in the 263 ESTs were converted into 31 pyrosequencing-based markers for Steptoe/Morex, 76 for Oregon Wolfe and 34 markers common to both populations, for a total of 141 SNP markers (Table 1).
Table 1 Marker frequency and map length of the individual mapping populations for deriving the integrated map

\begin{tabular}{lcccccc}
\hline & \multicolumn{2}{c}{ SM } & \multicolumn{2}{c}{ OWB } & \multicolumn{2}{c}{ integrated } \\
\hline Chromosome & Marker & cM & Marker & cM & Marker & cM \\
\hline $1 \mathrm{H}$ & 13 & 148.7 & 24 & 148.8 & 32 & 149.7 \\
\hline $2 \mathrm{H}$ & 15 & 135.8 & 22 & 155 & 28 & 155.3 \\
\hline $3 \mathrm{H}$ & 12 & 135.2 & 14 & 178.7 & 21 & 159.2 \\
\hline $4 \mathrm{H}$ & 3 & 107.4 & 8 & 123.2 & 9 & 127.2 \\
\hline $5 \mathrm{H}$ & 10 & 154.6 & 18 & 202.1 & 22 & 198.8 \\
\hline $6 \mathrm{H}$ & 5 & 96.9 & 8 & 104.6 & 10 & 141.4 \\
\hline $7 \mathrm{H}$ & 7 & 135.4 & 16 & 154.1 & 19 & 140.1 \\
\hline & 65 & 914 & 110 & 1066.5 & 141 & 1071.7 \\
\hline
\end{tabular}

Of the 20 functional gene categories represented among the 613 initially selected ESTs, 17 classes were retained among the genes tagged by the 141 markers (Additional file 1). Genes involved in carbohydrate, amino acid metabolism, hormone signalling, storage protein synthesis and the response to desiccation, as well as a number of transcription factors were particularly common (Additional file 1). Genotypic data associated with both the 141 de novo SNP markers (GBS3120-GBS3260), and with an established set of 140 GBS (GBS0001-GBS0921; [10]) and 71 BIN markers were then used to construct a 352 marker-based map (Figure 1), in which the BIN markers were situated as expected [10,23]. The only change in GBS marker order occurred on chromosome arm 3HL, where GBS0538 mapped distal, rather than proximal to $\mathrm{ABC} 161$ [10]. The genetic length of each chromosome ranged from $127.2 \mathrm{cM}(4 \mathrm{H})$ to $198.8 \mathrm{cM}$ $(5 \mathrm{H})$, and the overall map length was 1,072 cM (Table 1). Given the unequal genomic distribution of the marker loci, marker development was focussed on chromosomes $1 \mathrm{H}$ (32 loci) and $2 \mathrm{H}$ (28 loci), because these chromosomes are known to harbour drought-related QTL (unpublished data and $[3,4,6]$ ). For example, Teulat et al. [4] identified a QTL for drought related traits at the SSR marker Ebmac684 on $2 \mathrm{H}$ analysing grain material from field grown barley from an environment with limited water availability especially during the grain filling period. The marker Ebmac684 maps close to ABC468 [24], in a chromosomal region where several de novo markers representing putative candidate genes were mapped. These genes encode transcription regulators (GBS3215, GBS3217, GBS3224), a cytochrome protein (GBS3138), a protein kinase (GBS3167) and the starch branching enzyme (GBS3257). Chromosomes $4 \mathrm{H}$ (nine loci) and $6 \mathrm{H}$ (ten loci) contained the least de novo marker, while 21, 22 and 19 loci were mapped to chromosomes $3 \mathrm{H}, 5 \mathrm{H}$ and $7 \mathrm{H}$, respectively. Each member of the pairs of sequences GBS3141/GBS3216, 


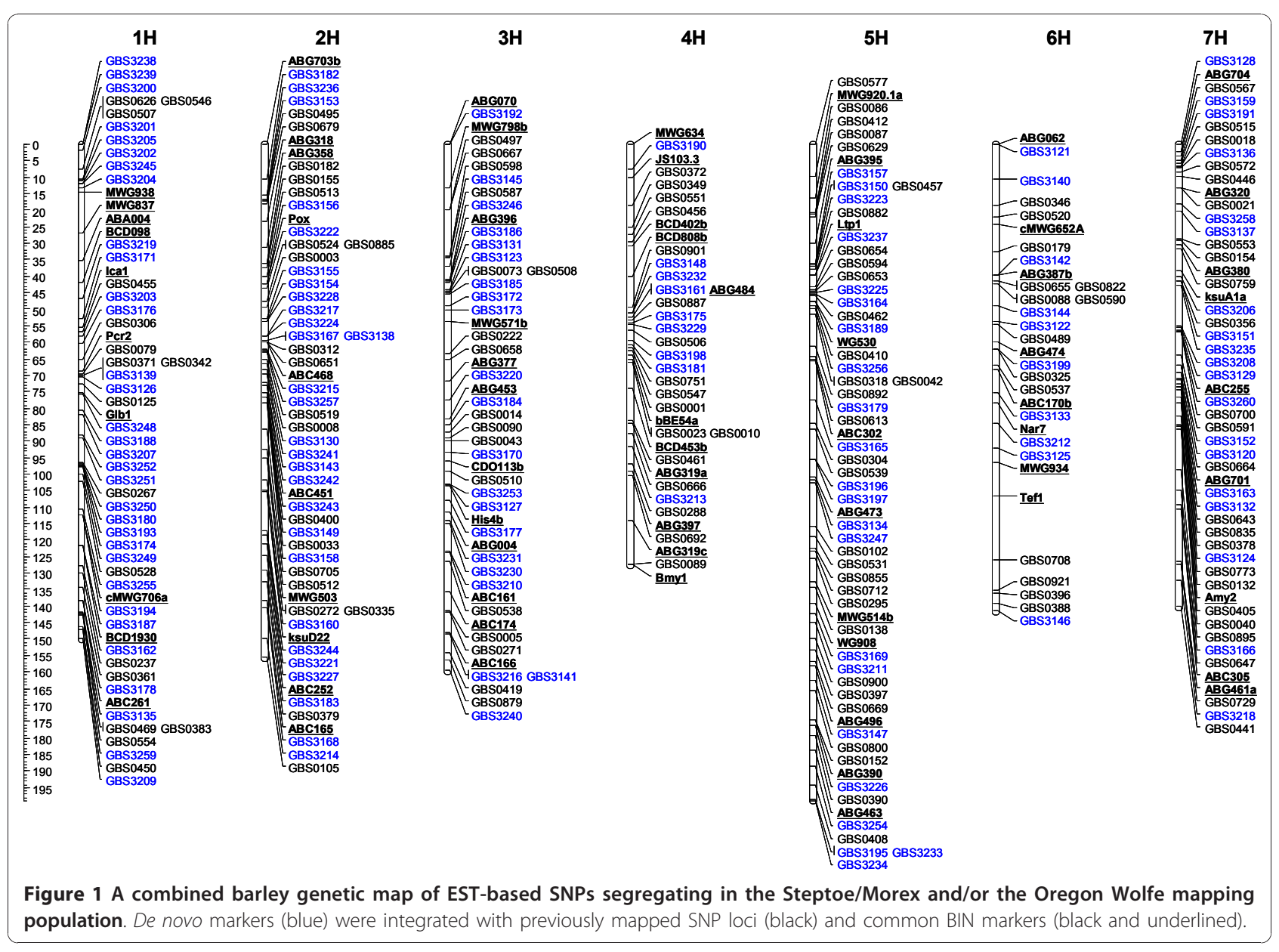

GBS3193/GBS3250, GBS3129/GBS3260, and GBS3150/ GBS3223 was derived from the same EST, and thus mapped to the same position (Additional files 3 and 4). The pairs GBS3230/GBS3231, GBS3172/GBS3173 and GBS3154/GBS3155/GBS3228 each are based upon different EST clusters but represent the same gene as they do not overlap due to shorter contigs, and mapped to a single chromosome bin (Additional files 3 and 4).

\section{Overlap with other barley SNP maps}

Only seven of the previously mapped abiotic stress related barley genes belong to the present map of droughtresponsive 141 de novo SNP markers [7] (Additional file 4). GBS3193 and GBS3250 belong to the same mapped abiotic stress marker scsnp04853, mapped to chromosome $1 \mathrm{H}$ in [7]. On chromosome $2 \mathrm{H}, \mathrm{GBS} 3244$ is covered by scsnp00592, GBS3138 by scsnp01644 and GBS3158 by scsnp03343. GBS3198 (chromosome 4H) corresponds to scsnp06435, and GBS3247 (chromosome 5H) to scsnp14350. Six of the seven overlapping markers mapped to their expected chromosomal BIN, but GBS3244 appeared to lie proximal, rather than distal to ABC252.
Taken the consensus transcript map in [10] five of the de novo SNP loci are represented there, namely GBS3178/ GBS0237 (chromosome 1H), GBS3158/GBS0400 (chromosome 2H), GBS3246/GBS0073 and GBS3170/GBS0043 (chromosome 3H), and GBS3128/GBS0018 (chromosome $7 \mathrm{H})$. A further $14 \mathrm{GBR}$ or GBM markers identified the same loci as the de novo SNPs, but two (GBS3139 on chromosome $1 \mathrm{H}, \mathrm{GBR} 1494$ on chromosome $2 \mathrm{H}$; and GBS3207 on chromosome $1 \mathrm{H}, \mathrm{GBR} 1571$ on chromosome $2 \mathrm{H})$ had a discrepant chromosome location. The pairs GBS3253/GBR0625 and GBS3185/GBM1405 all mapped to chromosome $3 \mathrm{H}$ but to different bins (Additional file 4). Another high-density transcript linkage map based on a total of 2890 SNP, CAPS and INDEL markers was published by Sato et al. [9]. According to unigene IDs, 31 GBS markers show overlap with 28 loci of the present map. Finally, 67 of the 2,943 SNP loci present on the Close et al. [8] map correspond to GBS marker(s), with no discrepancies in terms of chromosomal location. Marker 1_0686 (matching GBS3207 and GBR1571 [10]) was located to chromosome $1 \mathrm{H}$, thereby confirming the position of GBS3207. In summary, 52 of the 141 de novo SNP 
loci of drought-responsive genes represent novel means for characterizing the genetic basis of drought tolerance in barley and they may also provide useful information for the construction of the barley physical map as the next step towards genome sequencing.

\section{The drought stress response of mapped transcripts over development}

To reveal the drought stress response of mapped transcripts during various stages of development, we normalized the expression data by utilizing the publicly available expression data sets deposited in Gene Expression Omnibus (GEO) from five (GEO accession series number: GGSE3170) and 21 (GSE6990) day old seedlings, flag leaves post anthesis (GSE15970), green spike tissues (awn, lemma and palea, GSE17669) and own data from developing grain during 20 days after fertilization (DAF). A range of barley cultivars has been used to generate these data, including the drought tolerant cv. Martin and the susceptible cv. Moroc9-75, parents of mapping and $\mathrm{AB}$ populations (OWB-D, OWB-R, Morex, Brenda and Hs584). The clustering process identified three major groups: groups 1 and 2 contained genes which are up-regulated as a result of drought stress, while the ones in group 3 were down-regulated (Figure 2). While group 2 genes showed up-regulation mostly in early vegetative tissues, group 1 members were up-regulated across all developmental stages, and were expressed in a range of organs (seedlings, flag leaf, lemma, palea, and awn and to a lesser extent in the developing grain). Thus, group 1 genes could be considered to represent a core set of drought responsive genes. The functional groups particularly overrepresented in groups 1 and 2 included transcription regulators, genes induced by abiotic stress, genes responsible for the synthesis of storage proteins and genes related to amino acid and carbohydrate metabolism, and ABA-induced hormone related genes, calculated by Fisher's exact test with a P-value cut off 0.01 (Figure 2 and Additional file 3).

\section{Regulators}

An ABA signalling gene (protein phosphatase 2C, marker GBS3123), a bZIP ABA-responsive element binding protein (GBS3212) were consistently up-regulated by drought throughout development in barley (Figure 3). In A. thaliana, protein phosphatase $2 \mathrm{C}$ regulates a Snf1related kinase [25], and mediates signal transduction to an ABF2 transcription factor [26]. Thus in barley, it seems likely that an ABA signalling pathway orchestrates the adaptive response to drought, not just at the seedling stage but also in the flag leaf, awn, lemma and palea (Figure 3). In addition several Ras family Gproteins (GBS3161, GBS3162, GBS3163, GBS3245) thought to be involved in ABA signalling are found to be induced in 21 day seedlings and flag leaf (Figure 3).
Several ABA-induced late embryogenesis abundant proteins (GBS3120, GBS3121, GBS3248) were induced to drought in seedlings (Figure 3), and these have been shown previously to be involved in desiccation tolerance [27]. A number of ABA signalling related genes were included in the genetic map (Additional file 3). Other transcription factors were induced by drought in a nonorgan specific manner; these included AP2/ERF II (GBS3206), VII (GBS3208), VIII (GBS3207), bHLH (GBS3210), bZIP (GBS3212, GBS3211), MYB (GBS3142, GBS3145, GBS3219), NAC (GBS3146, GBS3147) and several other unclassified factors (Figure 3). The specific function(s) of most of these regulators remains unclear, but their up-regulation by drought stress indicates that they probably do play a role in the plant's response to water deficit.

\section{Abiotic stress induced genes}

Genes encoding dehydrin 9, universal stress proteins, hydrophobic proteins and various classes of heat shock proteins (HSPs) were induced by drought across all the developmental stages (Figure 2 group 1). Among the HSPs were HSP70 (GBS3180); HSP81-1 (GBS3182) and HSP26 (GBS3181), which mapped, respectively, to chromosomes $1 \mathrm{H}, 2 \mathrm{H}$ and $4 \mathrm{H}$ (Additional file 3). Other HSPs were not so generally up-regulated by drought. The up-regulation of HSP is consistent with their presumed protection of proteins from oxidative damage induced by drought stress [28].

\section{Drought response of mapped transcripts contributing to seed quality}

Barley grain storage proteins comprise a mixture of four distinct prolamin polypeptides: the B- and $\gamma$ - (sulphurrich) hordeins, the $\mathrm{C}$ - (sulphur-poor) hordeins and the high molecular weight D-hordeins. The hordein genes are known to be organised in clusters encoding the B-hordeins (Hor2 and Hor4), C-hordeins (Hor 1), $\gamma$-hordein (Hor5) and D-hordein (Hor3) which are all located on chromosome $1 \mathrm{H}$ [29]. The present genetic map showed that GBS3200, a marker for B1-hordein, lay near the telomere of chromosome $1 \mathrm{H}$, while GBS3205 (marking another B1-hordein) was linked closer to GBS3202 (B3-hordein), around $11 \mathrm{cM}$ distant from GBS3201 ( $\gamma$ 1-hordein). A third B-hordein marker (GBS3204) was placed further apart, closer to $\gamma 3$-hordein. Thus the B-hordein gene family is represented by at least three different loci on the short arm of chromosome $1 \mathrm{H}$, while the $\gamma$-hordein genes also map to two distinct loci on the same chromosome arm (Figure 4).

The regulation of hordein family gene transcription includes DNA methylation [30,31] and the concerted action of distinct transcription factor families [32,33]. The expression of all the sulphur-rich hordein genes was promoted by drought in the awn, lemma and palea 


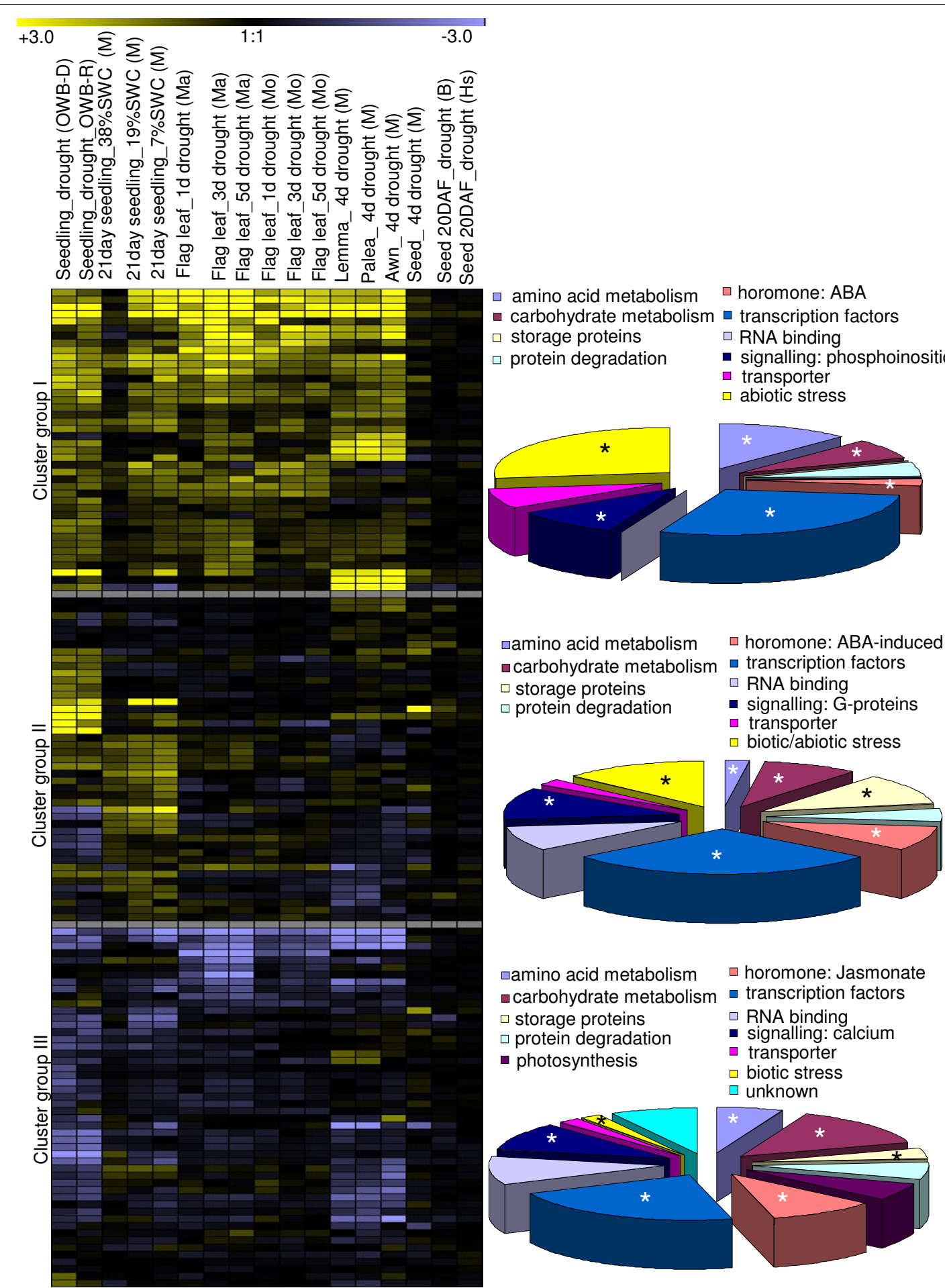

Figure 2 Expression profiles of barley genes responsive to drought. Expression ratios (drought vs control) are colour-coded: dark yellow $>6$ fold up-regulated, black no change, violet $>6$ fold down-regulated. The proportion of genes within a given functional transcript group is shown in the corresponding pie chart on the right with significantly overrepresented gene categories marked by star symbol. Each gene is represented as horizontal row (for order, see Additional file 3) and developmental stages are detailed in the vertical columns (d: days of exposure to drought and \%SWC: soil water content). Gene expression data refer to cvs. Brenda (B), Morex (M), Morocco (Mo), Martin (Ma), Oregon Wolf BarleyDominant (OWB-D), Oregon Wolf Barley-Recessive (OWB-R), Hs (H. spontaneum HS584). Expression data from individual replications are given in Additional file 3. 

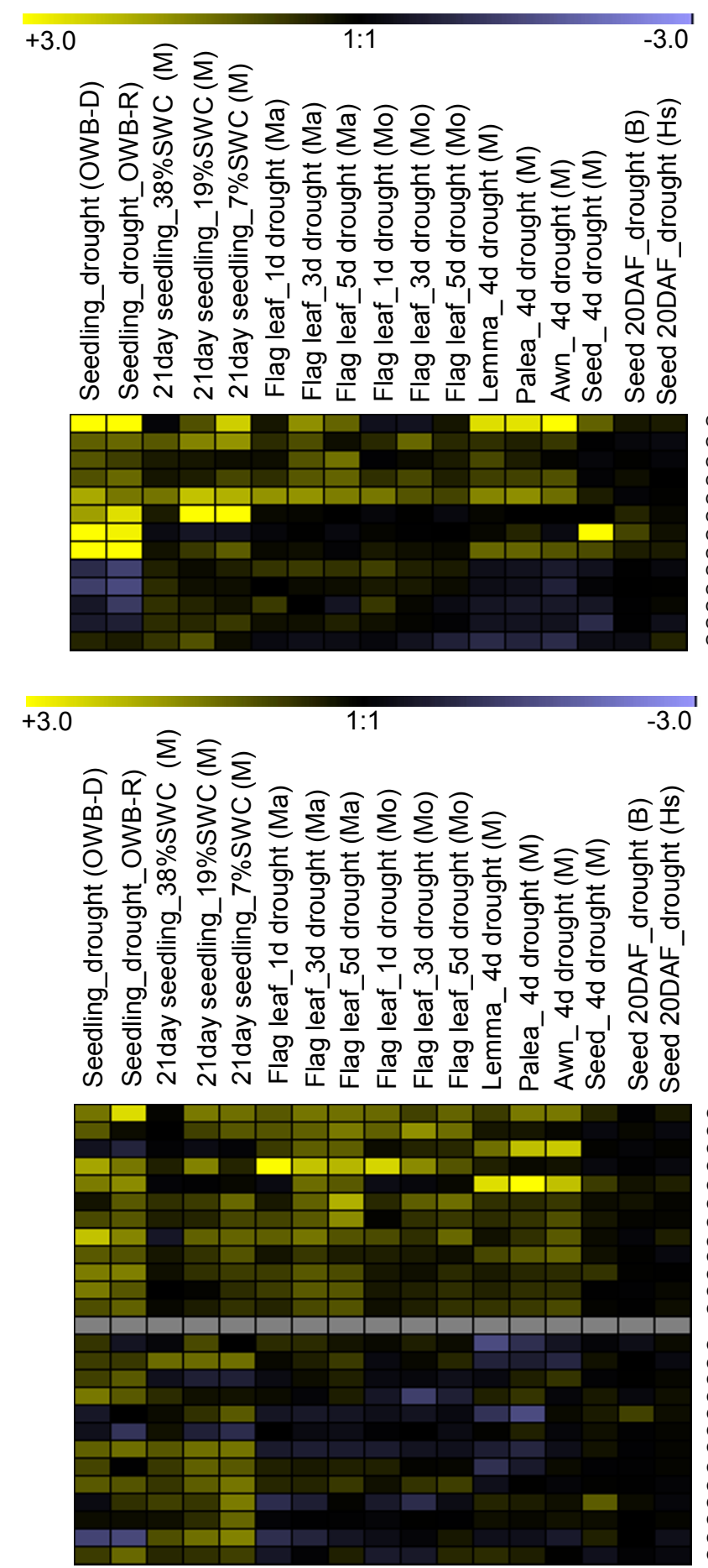

GBS3160: Contig7501_s_at: signalling.calcium

GBS3165: Contig4218_at: signalling.phosphinositides

GBS3164: Contig3562_at: signalling.phosphinositides

GBS3166: Contig13498 at: signalling.receptor kinases.DUF 26

GBS3123: Contig9585 at: hormone metabolism.abscisic acid.signal transduction GBS3121: Contig6276_s_at: hormone metabolism.abscisic acid.induced-regulated GBS3248: Contig1830_at: hormone metabolism.abscisic acid.induced-regulated GBS3120: Contig8149_at: hormone metabolism.abscisic acid.induced-regulated GBS3162: Contig3165_at: signalling.G-proteins

GBS3161: Contig5611 at: signalling.G-proteins

GBS3163: Contig10901 at: signalling.G-proteins

GBS3245: Contig3167_s at: signalling.G-proteins

GBS3247: Contig14350_at: signalling.receptor kinases.Catharanthus roseus-like RLK1

GBS3206: HA11J15u_s_at: AP2/EREBP family

GBS3208: Contig3914 s at: AP2/EREBP family

GBS3210: Contig13678_s_at: bHLH,Basic Helix-Loop-Helix family

GBS3212: Contig21149_s_at: bZIP transcription factor family

GBS3141: Contig8202_at: C3H zinc finger family

GBS3145: Contig8571_at: MYB domain transcription factor family

GBS3142: Contig9706 at: MYB-related transcription factor family

GBS3147: Contig3361_at: NAC domain transcription factor family

GBS3148: Contig7464_at: putative DNA-binding protein

GBS3151: HVSMEf0011105r2_s_at: transcription factor unclassified

GBS3157: Contig10344_at: transcription factor unclassified

GBS3207: Contig6636_at: AP2/EREBP family

GBS3211: Contig9253_at: bZIP transcription factor family

GBS3213: Contig13989_at: C2C2(Zn) DOF zinc finger family

GBS3214: Contig20418_at: C2C2(Zn) DOF zinc finger family

GBS3139: Contig13200 at: C2C2(Zn) GATA transcription

GBS3217: Contig5444_s_at: GRAS transcription factor family

GBS3143: Contig17371_at: Histone acetyltransferases

GBS3219: Contig8132_at: MYB domain transcription factor family

(1)

GBS3149: Contig6099_at: putative DNA-binding protein

Figure 3 Expression profiles of mapped barley genes up-regulated by drought stress. Upper panel: hormone and signalling genes, lower panel: transcription factor families. For abbreviations, see Figure 2 legend. Expression data from individual replications are given in Additional file 3.

(Figure 4). Hordein transcripts first appear in the endosperm at 12 days post anthesis, peaking in expression by 16 days, and then maintaining this level until grain maturity $[34,35]$. The B1-hordein genes were induced in developing seeds by drought stress in cv. Brenda, but less prominently so in HS584 (Figure 4), indicating distinct differences in B-hordein gene expression between cultivated barley and its wild relative. Correspondingly, the seed nitrogen/protein content also increased under drought in Brenda but not in HS584. However, the 


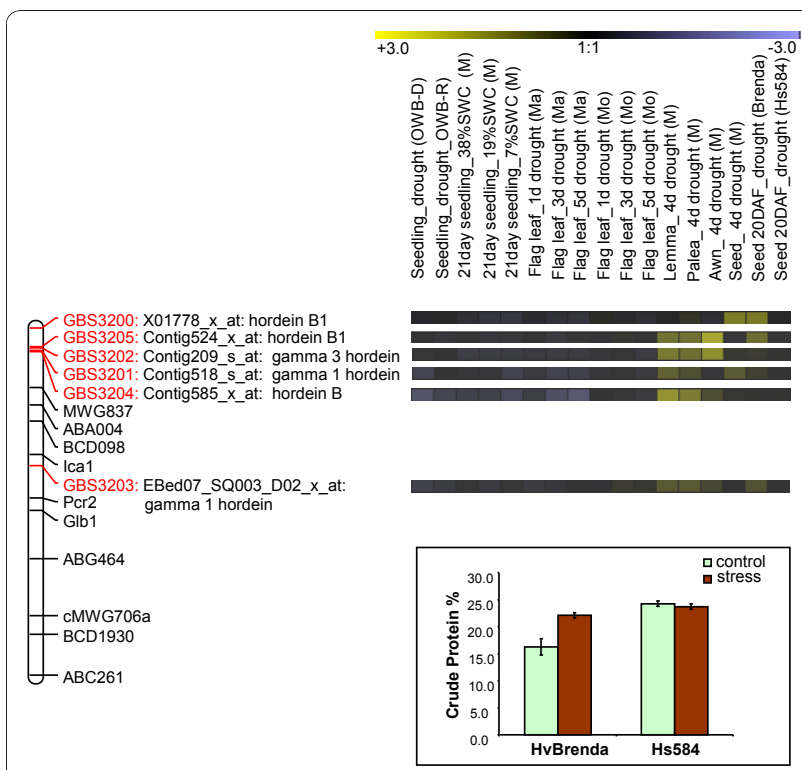

Figure 4 The cluster of sulphur-rich hordein genes on the short-arm barley chromosome $1 \mathrm{H}$ (left panel) and their corresponding expression profiles during development. For abbreviations, see Figure 2 legend. Expression data from individual replications are given in Additional file 3. In the lower panel, percent crude protein estimated based on seed nitrogen (N\%) for the two parents of introgression line population (H.vulgare Brenda and $H$. spontaneum 584) from control and drought stress treatments is presented. absolute levels remained high in the control plants (Figure 4).

In contrast, the down-regulation of the gene family members of key starch biosynthesis genes, sucrose synthase, ADP-glucose pyrophosphorylase are downregulated by terminal drought stress in the post anthesis period during 20 DAF (Figure 5A). Several genes associated with the activity of the starch branching enzyme became activated by terminal drought stress, which has implications for the synthesis of amylopectin. Certain genes involved in starch degradation (e.g., those encoding sd1- $\beta$-amylase and chloroplast-targeted $\beta$-amylase) were also induced by drought stress, which points to a concerted fine tuning of starch biosynthesis and degradation in impairing seed starch accumulation and seed quality. However, many genes associated with carbohydrate metabolism including the genes encoding sucrose synthase type I (GBS3129), ADP-glucose pyrophosphorylase large subunit (GBS3259) and starch branching enzyme class II (GBS3257) were up-regulated by drought stress in seedlings, the flag leaf, the awn, lemma and palea (Figure 5A). The production of starch in vegetative tissues of Arabidopsis thaliana has been found to be negatively correlated with plant biomass [36]. Likewise, we might expect that starch accumulation in vegetative tissues negatively affects plant growth under drought stress.

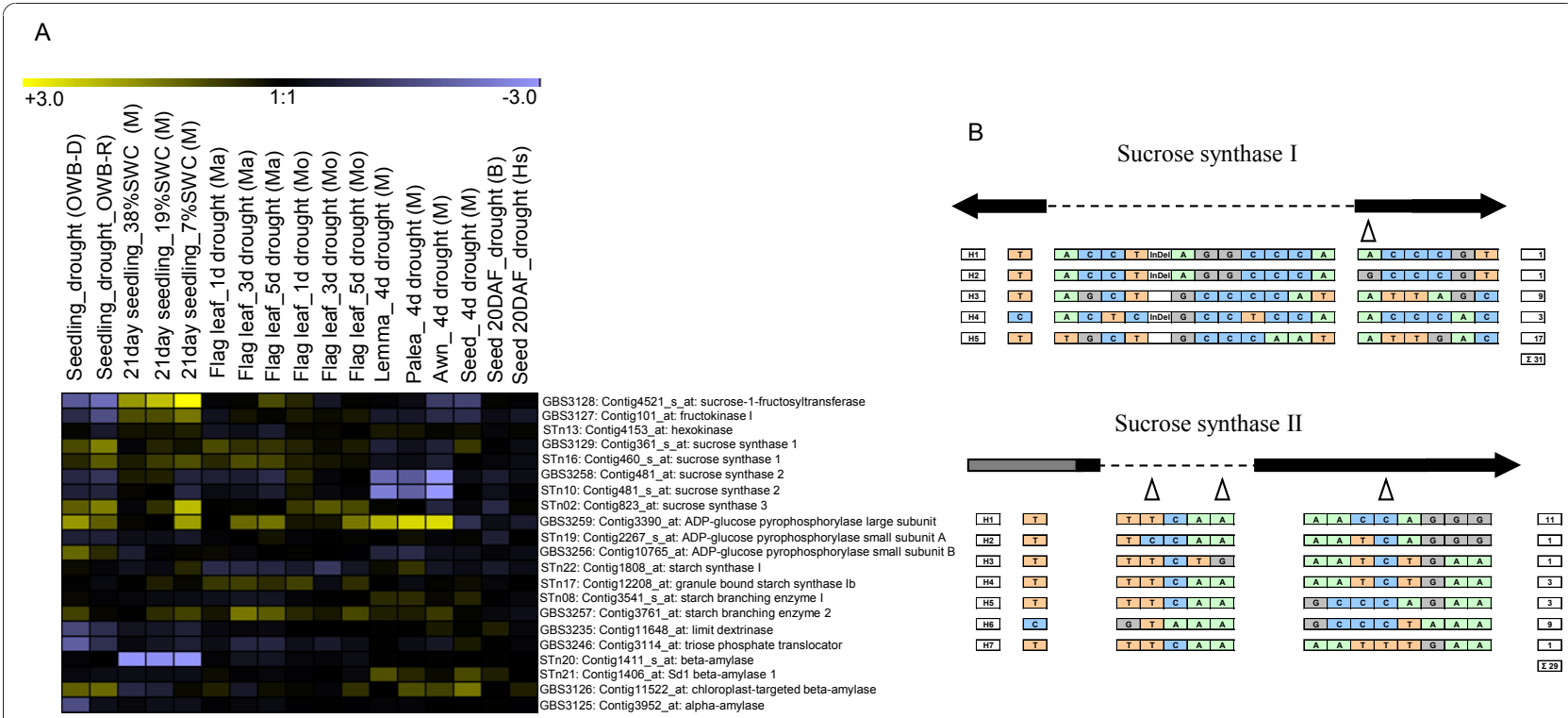

Figure 5 The expression profiles of a selection of starch biosynthesis/degradation genes responsive to drought during development (panel A). For abbreviations, see Figure 2 legend and expression data from individual replications are given in Additional file 3 . The location of SNPs and the resulting haplotypes (H) present in both sucrose synthase types I (GBS3129) and II (GBS3258) genes are given in panel B. Black arrows indicate exonic regions and grey bars untranslated regions. Introns are represented by dashed lines. Shown below are the haplotype groups with the respective polymorphisms and the number of lines per group. Triangles indicate accession-specific SNPs. Haplotypes of all the genes detailed in Additional file 5. Correlation of seed starch content under drought to specific haplotypes of sucrose synthase type II is given in Additional file 6 . 
Table 2 Haplotype details for the core set of starch biosynthesis/degradation genes

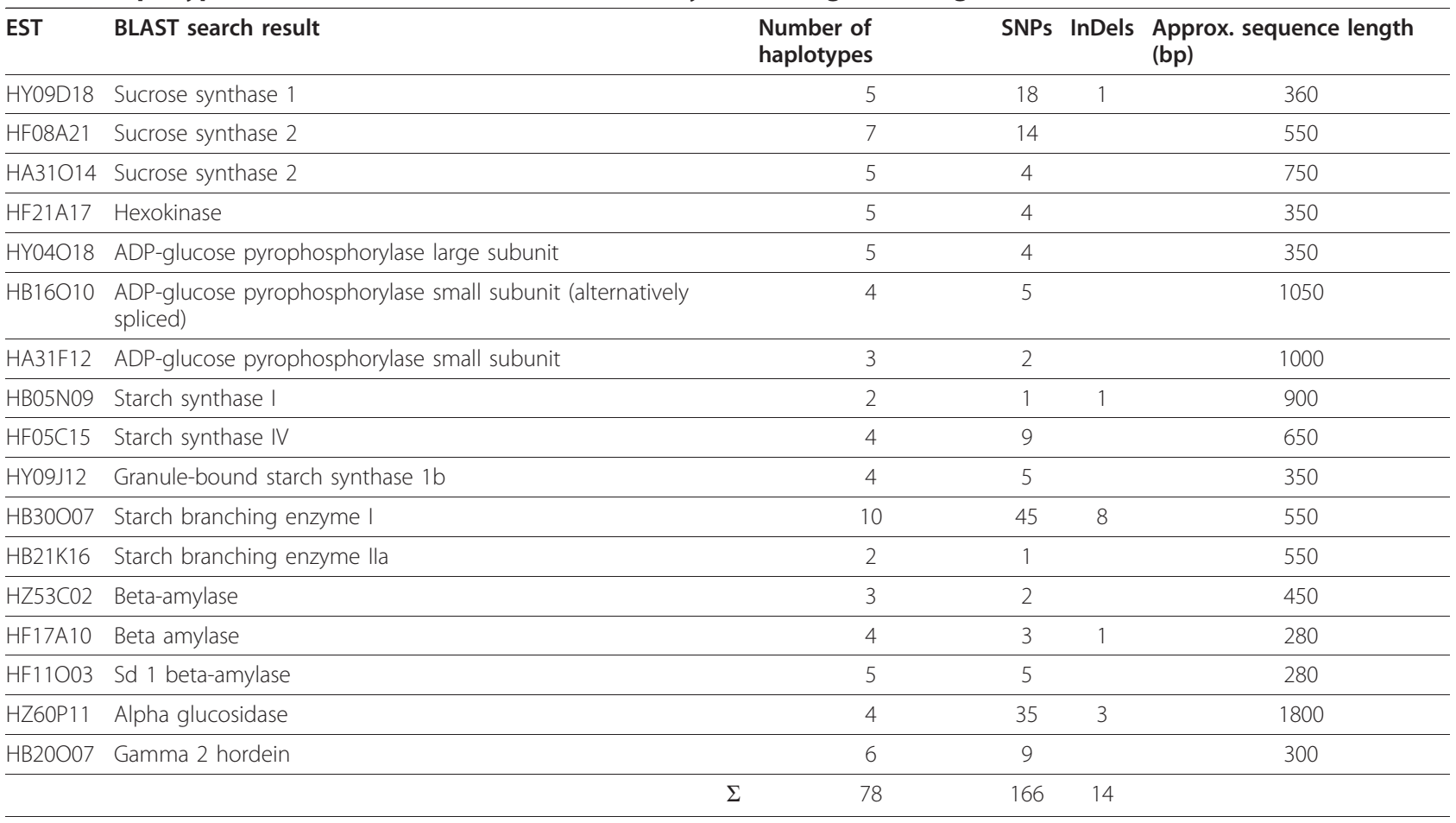

Haplotype analysis of carbohydrate metabolism genes

A detailed analysis of sequence variants within 17 starch biosynthesis/degradation genes was conducted for a core set of 32 accessions, which included landraces, elite breeding lines, the mapping population parents and $H$. spontaneum. This delivered 180 polymorphic sites (SNPs and indels) across both intronic and exonic sequence, and led to the recognition of 78 haplotypes (Table 2). Overall the elite breeding lines, including $\mathrm{cv}$. Brenda, showed little haplotypic variation, but the remaining materials fell into a number of haplotype groups indicating broader genetic diversity. Figure 5B summarizes the variation present within the genes encoding sucrose synthase types I (CR-EST:HY09D18, marker: GBS3129) and II (CR-EST:HA31O14, CR-EST: HF08A21; GBS3258) whereas the haplotyping data for the remaining genes are listed in Additional file 5.

Within the $360 \mathrm{bp}$ re-sequenced region of the sucrose synthase type I amplicon, 18 SNPs and a 3 bp indels were found. Among the SNPs, 11 were situated within an intron and seven (six synonymous) within an exon; the single non-synonymous SNP was a transition variant present in $\mathrm{cv}$. Morex, which converted a glycine residue to a serine. The accessions could be classified into five haplotypic groups (H1-H5), the largest of which (H5) included all the elite breeding lines and half of the remaining $H$. vulgare accessions. $\mathrm{H} 2$ contained only one entry (cv. Morex), as did H1 (HS584). H3 captured several $H$. vulgare and the other $H$. spontaneum accessions, as well as the Oregon Wolfe dominant parent. The Oregon Wolfe recessive parent fell into $\mathrm{H} 4$ along with two other $H$. vulgare lines (Additional file 5).

GBS3258 represented about 550 bp of the sucrose synthase type II sequence, and the re-sequencing of 29 accessions generated 14 SNPs. These allowed the recognition of seven haplotypes (H1-H7), of which $\mathrm{H} 2, \mathrm{H} 3$ and $\mathrm{H} 7$ each contained only one accession. The elite breeding lines were split among the two major groups $\mathrm{H} 1$ and $\mathrm{H6}$, along with most of the $H$. vulgare accessions, although $\mathrm{H6}$ also included ISR42-8, an H. spontaneum accession. Groups $\mathrm{H} 4$ and $\mathrm{H} 5$ each contained three accessions, the former containing the remaining $H$. spontaneum accessions, and the latter the remaining $H$. vulgare ones.

The relatively high level of haplotype diversity in these two sucrose synthase genes among non-elite lines suggests that these genes have experienced selection processes during the course of domestication and farmer's selection. However, for improving sink strength specific haplotypes (H5 from sucrose synthase I, H1 and H6 from sucrose synthase II) were fixed in the elite lines during the breeding. In maize, key starch biosynthesis enzymes and soluble carbohydrates were measured from field grown samples from hundred recombinant inbred lines and revealed major QTLs close to the locus sucrose synthase $(S h 1)$ gene known to be linked to improved starch accumulation [37]. To confirm the importance of Sh1 locus, sucrose synthase gene 
polymorphisms was analyzed in 45 genetically unrelated maize lines. Therein, the Sh1 locus was also found to significantly associate with higher starch and amylase content as well as grain matter from multi-location field trials [37]. In the present study also a high level of allelic diversity was detected in the genes encoding sucrose synthase I, sucrose synthase II, starch branching enzyme I and $\alpha$-glucosidase, while the genes encoding both the small and large subunits of ADPglucose pyrophosphorylase were rather non-polymorphic (Additional file 5).

Haplotype variation was also used to estimate the extent of the genetic separation between cv. Brenda and HS584. Among the 13 informative sequences, three harboured non-synonymous exonic SNPs. Two neighbouring SNPs within the granule bound starch synthase Ib gene [CR-EST:HY09J12] were present in both HS584 and a number of the barley accessions, while the SNPs present in both the ß-amylase [CR-EST:HF11O03] and the $\gamma$-2 hordein [CR-EST:HB20O07] genes were unique to HS584. Another four genes (sucrose synthase type I [CR-EST:HY09D18] and type II [CR-EST:HA31O14, CR-EST:HF08A21], ADP-glucose pyrophosphorylase small subunit sequence [CR-EST:HB16O10], and starch branching enzyme I [CR-EST: HB30O07]) were found to contain synonymous exonic substitutions. Intronic SNPs were also detected in most of the genes, including the ADP-glucose pyrophosphorylase small subunit sequence [CR-EST:HB16O10], a gene known to undergo alternative splicing [38]. These data confirm that wild barley alleles own the capability to alter protein sequences (non-synonymous SNPs), codon usage (synonymous SNPs) and the splicing process (intronic SNPs) and emphasize the potential of the Brenda/ HS584 introgression line population to serve as a model for the investigation of favourable wild barley alleles.

\section{Intraspecific variation of grain starch content under terminal drought}

Identifying the molecular basis of phenotypic variation can provide improved insights into the mechanisms responsible for key agronomic traits such as grain yield stability. Thus patterns of starch accumulation during terminal drought were monitored for a diverse set of 50 barley accessions. A high genetic variation for grain starch content was observed (Figure 6). The starch content of the non-stressed barley landraces varied from $450-680 \mathrm{mg} / \mathrm{g}$ dry weight, while among the elite breeding lines, the range was $514-648 \mathrm{mg} / \mathrm{g}$ (Additional file 5 and Figure 6). Within gene bank accessions of $H$. vulgare and $H$. spontaneum, two major classes were found; one class suffered a reduction of up to $45 \%$ in the amount of starch accumulated under terminal drought conditions, whereas the other performed well in both well-watered and terminal drought conditions (Figure 6). Unlike the wild barleys and the landraces, the sample of elite breeding lines showed little variation for starch accumulation, although

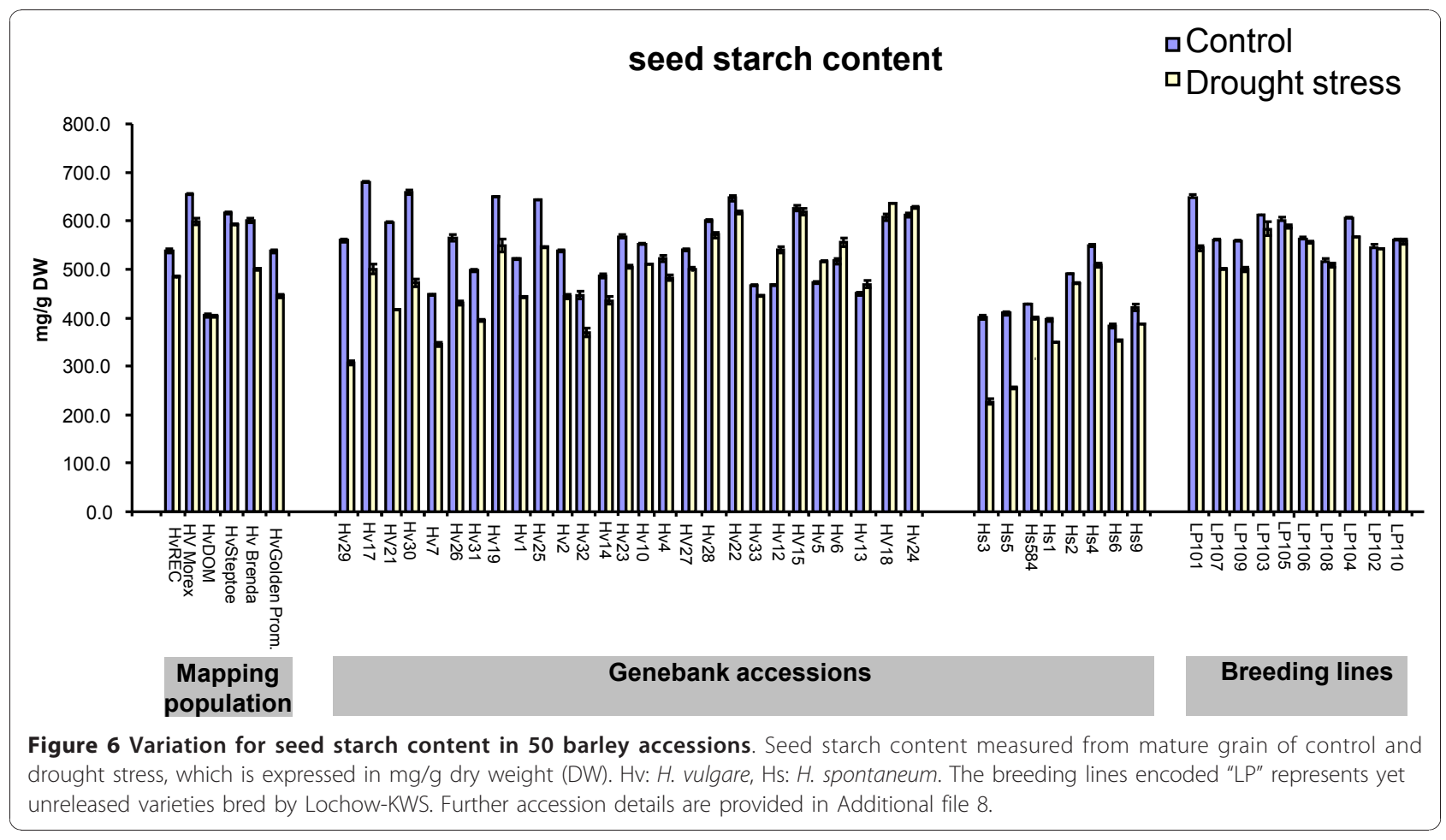


many performed well under terminal drought stress. Three accessions (LP101, LP107 and LP109) suffered a slight reduction in grain starch content and, consequently, thousand grain weight (TGW) when challenged with terminal drought stress under both field and green house conditions (Additional file 5). Interestingly, those lines which showed dramatic reduction of starch content under terminal drought in comparison to their respective controls possess haplotypes H3 (Hv32), H4 (Hs3, Hs5, Hv10) and H5 (OWB-DOM, Hv29, Hv30) from sucrose synthase II gene (starch content of control versus stress with low correlation of $\mathrm{R}^{2}=0.4$ ) and lines possessing haplotype H6 (ISR42_8, Hv13, Hv20, Hv22, LP103, LP104, LP106, LP107, LP110) from sucrose synthase II gene correlate positively to optimum starch accumulation under both control and drought treatments (with $\mathrm{R}^{2}=$ 0.9 at a significance level of $\alpha=0.01$ using Steiger's Z-test for Pearson correlation) [Additional file 6]. Similarly, we also noticed a higher genetic variation for TGW of barley landraces not only under control conditions but also under drought stress (Additional file 7). Moreover, global correlation analysis between seed starch content and an average of TGW obtained from multi-location field trials from two consecutive years (2007 and 2008) using both methods (water withhold and potassium treatments) and green house screening for all genotypes under drought stress conditions signifies correlation with $\mathrm{R}^{2}=0.72$ at a significance level of $\alpha=0.01$ using Steiger's Z-test for Pearson correlation (Figure 7). The origin and IG-number is provided for all 50 barley accessions in Additional file 8.

\section{Conclusions}

The genetic mapping of 141 drought regulated ESTs has extended the abiotic stress SNP map of barley [7] by a further 134 novel markers. An extensive expression analysis of these ESTs at various developmental stages for drought response and across a range of barley accessions resulted in creating an expression map for genetically mapped markers. The mapped candidate genes

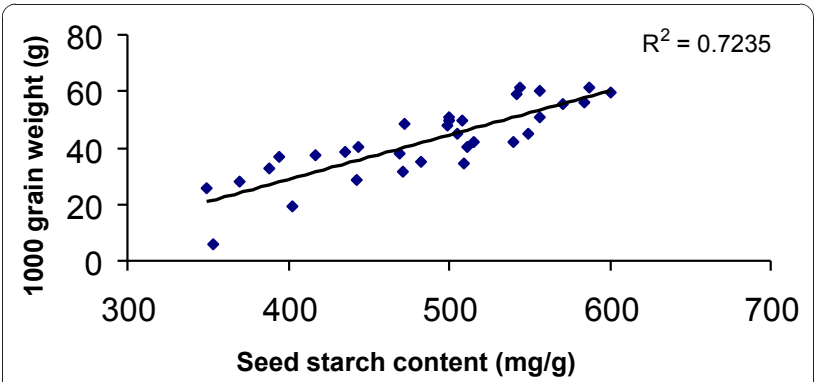

Figure 7 Scatter plot and correlation analysis of seed starch content and thousand grain weight (TGW) under terminal drought stress. For further details refer 'Methods' section. have been reported to co-segregate with drought related traits, which fall into diverse functional categories like stress response (e.g. dehydrin $[39,40])$, transcription factors (e.g. CBF [5]), carbohydrate metabolism (e.g. sucrose synthase [3]) and many more [3,6,41,42]. The map also disclosed an interesting correlation between several clusters of sulphur-rich hordeins on the short arm of chromosome $1 \mathrm{H}$ and their co-expression, potentially linked to methylation based regulation [30,31].

The haplotype structure of 17 starch biosynthesis/ degradation genes was explored, revealing that the genes encoding sucrose synthase (both types I and II) and starch synthase were surprisingly variable in wild barley and landraces. Superior alleles related to haplotype H5 from sucrose synthase I and H6 from sucrose synthase II were found to be present in the studied breeding lines too, selected for improved performance. This observation provides additional evidence that these alleles may be causally associated with improved starch accumulation under control as well as terminal drought stress conditions. The gained knowledge represents a valuable source for the development of functional markers to assess larger collections of barley accessions for the correlation of relevant haplotypes of starch biosynthesis/ degradation genes to seed starch content under drought and, therefore, for further improvement of barley cultivars in terms of improved grain weight.

\section{Methods}

Plant material, starch and DNA extraction

The eight barley accessions from which ESTs were resequenced were the parents of mapping populations crs. Steptoe and Morex [43], the parents of the Oregon Wolfe population [44] and the parents of $A B$ populations cv. Scarlett and ISR42_8 [22], and cv. Brenda and the H. spontaneum accession 584 [21]. The Steptoe/ Morex and Oregon Wolfe mapping populations comprised 80 and 94 individuals, respectively. Total genomic DNA was extracted from 4-6 g young leaf material, using the protocol described in [45].

A set of 50 barley accessions was assembled from the IPK Gatersleben and the ICARDA genebanks, and these, along with $\mathrm{cv}$. Brenda and $H$. spontaneum accession 584 (HS584), were grown till flowering under a $16 \mathrm{~h}$ light $/ 20^{\circ} \mathrm{C}, 8 \mathrm{~h}$ dark $/ 15^{\circ} \mathrm{C}$ regime. Terminal drought stress was imposed for a period of three weeks beginning one week after fertilization (8 DAF) during the postanthesis period. The automatic watering procedure was monitored by a DL2e data logger (Delta T) with SM200 sensors connected to individual pots. This enabled to maintain the control plants at $60 \%$ soil moisture and drought stressed plants at $10 \%$ soil moisture. Mature seeds were harvested from the mature plants of control and drought stressed plants and estimated TGW using 
MARVIN seed counter. For each line, three independent replicates were maintained for both control and drought stress treatments and for each replicate seeds were pooled from five plants.

Starch was extracted from ground mature grains in $80 \% \mathrm{v} / \mathrm{v}$ ethanol at $60^{\circ} \mathrm{C}$, each followed by a centrifugation (15 min, 14,000 g). The final supernatant was discarded and the remaining pellet used for the quantification of starch content [46]. Starch content is measured from three replicates.

Crude protein content (\%) was obtained by multiplying seed N\% with the factor 5.83 [47]. Total seed N\% was measured using elemental analyzer (Vario EL; Elementar analyse system).

All 50 accessions were also subjected to drought stress in the field at breeding station, Nordsaat Böhnshausen over the two consecutive years (2007 and 2008) by following two different strategies. Strategy I: All genotypes were planted as two-row plots per entry with two replications in randomized blocks, directly on soil in a closed green house/rain shelter which completely protects rain fall. Control plants were irrigated four times during the period from seed set until seed filling. For imposing terminal drought stress, ten days post anthesis staged plants were subjected to water withhold by stopping irrigation until the end of grain development. Strategy II: All genotypes were planted as three-row plots per entry with two replications in randomized blocks. Control plants remained untreated. For mimicking drought stress treatments $10 \% \mathrm{w} / \mathrm{v}$ potassium iodide is sprayed to whole plant at ten days post anthesis. After reaching maturity, all the genotypes of the two replicates from two strategies were harvested by hand and TGW and seed quality was determined in Nordsaat seed quality laboratory.

Correlation analysis was carried out between TGW data and starch content under drought stress. To consider seasonal variability, lines in each year were $\mathrm{z}$-score normalized, and then variance was calculated across the years. The Z-score normalized TGW data for all accessions are shown as heat maps (Additional file 7). Those lines with too high variance levels were excluded from the correlation analysis. For the remaining lines, average values of TGW data were calculated across the years (2007 and 2008) from field and rain shelter as well as green house experiments. These averaged TGW data were correlated with the corresponding average values of green house replicates of seed starch content from drought treatments using the Pearson correlation measure. Statistical significance of the calculated $\mathrm{r}^{2}$ values was assessed using Steiger's z-test at a significance level of $\alpha=0.01$ [48].

\section{SNP discovery and detection}

For the sequences identified in the CR-EST database (clustering project g03) http://pgrc.ipk-gatersleben.de/cr-est/,
GeneRunner software http://www.generunner.net was applied to design PCR primer pairs each amplifying a 300$600 \mathrm{bp}$ fragment from an individual EST. Each $50 \mu \mathrm{l} \mathrm{PCR}$ contained 50-100 ng genomic DNA template, $1.5 \mathrm{mM}$ $\mathrm{MgCl}_{2}, 0.2 \mathrm{mM}$ dNTP, $10 \mu \mathrm{M}$ of each primer and $1 \mathrm{U}$ Taq DNA polymerase. After an initial denaturation of $96^{\circ} \mathrm{C} / 2$ min, the reactions were cycled 14 times through $94^{\circ} \mathrm{C} / 30$ $\mathrm{s}, 72^{\circ} \mathrm{C}\left(-1^{\circ} \mathrm{C} /\right.$ cycle $) / 20 \mathrm{~s}$ and $72^{\circ} \mathrm{C} / 90 \mathrm{~s}$, and then a further 27 times through $94^{\circ} \mathrm{C} / 30 \mathrm{~s}, 58^{\circ} \mathrm{C} / 20 \mathrm{~s}$ and $72^{\circ} \mathrm{C} / 90 \mathrm{~s}$, before a final extension step of $72^{\circ} \mathrm{C} / 3 \mathrm{~min}$. After checking for correct amplification, each reaction was then purified using a MinElute ${ }^{\mathrm{mm}} 96$ UF PCR Purification kit (Qiagen, Hilden, Germany) according to the manufacturer's instructions, and subjected to cycle sequencing from both ends using the relevant PCR primers. Cycle sequencing was performed with the BigDye Terminator v3.1 ready reaction cycle sequencing kit on an ABI $3730 \times 1$ sequencer (Applied Biosystems). The re-sequenced ESTs were aligned using the SeqMan tool within the Lasergene software package http://www.dnastar.com to identify SNPs. According to the annotation of polymorphisms, haplotype groups were determined for a core set of starch biosynthesis/degradation genes (Table 2).

SNP detection was carried out by pyrosequencing. Corresponding assays were designed with the Pyrosequencing ${ }^{\text {ma }}$ Assay Design Software Version 1.0.6 (Biotage AB, Uppsala, Sweden). Genomic DNA was amplified as above, except that one primer was biotinylated, and the extension step was shortened from $90 \mathrm{~s}$ to $30 \mathrm{~s}$. Streptavidin Sepharose ${ }^{\mathrm{m}} \mathrm{High}$ Performance (GE Healthcare Biosciences, Uppsala, Sweden) was used to obtain single stranded amplicons. SNP genotyping was performed using the PSQ HS 96A System (Biotage AB, Uppsala, Sweden). Further information on template preparation and the pyrosequencing protocol can be found in [49].

\section{Linkage mapping}

JoinMap $^{\circledR}$ v4 [50] was used to construct a genetic map based on a combination of the de novo Steptoe/Morex and Oregon Wolfe population SNP and already published genotypic data [10]. Recombination fractions were converted to cM using the Kosambi mapping function, with the following JoinMap settings: minimum LOD score $=1.0$, recombination threshold $=0.4$, ripple value $=01$ and jump threshold $=05$. For chromosomes $3 \mathrm{H}$ and $6 \mathrm{H}$, the marker order of the reference map [10] was chosen as the starting order.

\section{Affymetrix Barleyl GeneChip analysis}

To identify drought regulated gene sets at various stages of development, Affymetrix chip CEL files derived from both control and drought-treated seedlings (Series GSE3170), 21 day old plants (Series GSE6990), flag leaves (Series GSE15970) [17], awn, lemma, palea, and the early stages 
of the developing grain (Series GSE17669) [51] were downloaded and merged with in house expression data obtained from developing grain 20 DAF from cv. Brenda and HS584. RNA was obtained from two independent replicates. For each replicate seeds were pooled from five plants. The developing grain harvested from the central part of the spike from both control and drought treated plants of cv. Brenda and HS584 according to [52]. The RNA was isolated using the TRIzol reagent (Invitrogen GmbH, Karlsruhe, Germany) and RNAeasy columns (Qiagen, Hilden, Germany). Probe synthesis, labelling and hybridization were performed according to the manufacturer's protocols (Affymetrix). The expression of 22,000 genes extracted from all experiments was subjected to RMA normalization, applying a linear model via the limma package using R/Bioconductor functions in Robin software [53]. After normalization, $\log 2$ expression values were derived to generate fold differences between non-stressed and drought stressed organs from independent experiments. A nested multiple testing strategy was applied, using the BenjaminiHochberg P-value correction (P-value cut-off 0.05) to recognize significant differences in expression levels. A selection of 141 mapped genes was made from the 613 genes identified, and analysed for expression differences between watered and water withhold plants at various developmental stages. These log fold-change expression data is first subjected to hierarchical clustering and obtained clusters groups was refined by applying a $\mathrm{K}$-means clustering method according to [35]. Heat maps were generated using Genesis software [54]. The differentially expressed genes were functionally assigned according to [35]. Functionally overrepresented gene categories have been calculated by Fisher's exact test with a P-value cut off 0.01 [35].

\section{Additional material}

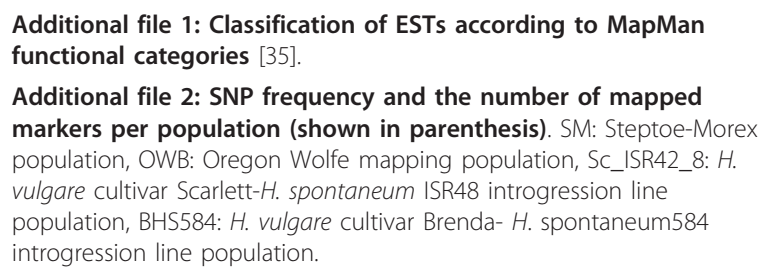

Additional file 3: Genes whose expression was induced/repressed by drought stress imposed at various stages of development. Their map location, putative function and normalized expression ratios (control vs drought stressed) are indicated. Statistical significance is indicated as 0 : non-significant, -1 significantly up-regulated, +1 significantly downregulated under drought.

Additional file 4: De novo SNP markers. int. ID: internal identification number, off. ID: official identification number, Chr.: chromosome location, unigene A35: unigene number, according to HarvEST:Barley assembly 35 http://harvest.ucr.edu, EST: identifier taken either from the CR-EST database, or from the Affymetrix Barley Contigs, alt. EST: identifier of alternative (orthologous) ESTs used for primer design, Locusprimer: the sequence of the PCR primers used for re-sequencing,

Pyrosequencingprimer: the sequence of the PCR primers used for pyrosequencing. "Redundancy to other SNP maps" indicates that the same gene target is present in one or more of four independent genetic maps; "Genotype" refers to the population tested; "Dispensation order" indicates the dispensation order applied in pyrosequencing.

Additional file 5: Haplotype groups based on observed variation in a set of 17 starch biosynthesis/degradation genes are provided. Additionally shown are the seed starch content values for each line under drought as well as control conditions. A detailed list of accessions, their origin and IG-number is also supplied.

Additional file 6: Correlations between seed starch content of control and drought stress from the accessions pertaining specific haplotypes in sucrose synthase.

Additional file 7: Heatmap of Z-score normalized thousand grain weight (TGW) data from drought stress experiments of field-grown (F), rain shelter (RS) from the two consecutive years (2007 and 2008). Red colour indicates higher TGW, yellow -medium and blue -lower TGW.

Additional file 8: Detailed list of accessions, their origin and IGnumber is provided.

\section{List of abbreviations}

AB: advanced backcross; DAF: days after fertilization; DW: dry weight; EST: expressed sequence tag; GBS: Gatersleben barley SNP; OWB: Oregon Wolfe Barleys; PCA: principal component analysis; RMA: robust multichip average; SNP: single nucleotide polymorphism; SM: Steptoe $\times$ Morex mapping population; TF: transcription factor; TGW: thousand grain weight

\section{Acknowledgements}

We thank Anette Heber, Jana Lorenz, Gabriele Einert and Katrin Blaschek for their excellent technical assistance and Prof. K. Pillen for providing samples of ISR42-8 and cv. Scarlett. We greatly appreciate the help of Dr. Marc Strickert for language improvement and for the help in bioinformatic analysis of field phenotypic data and correlation analysis. This research was financially supported by a grant from the German Ministry of Education and Research (BMBF) (Project GABI-GRAIN: FKZ; 0315041A).

\section{Author details}

'Leibniz-Institute of Plant Genetics and Crop Plant Research (IPK),

Corrensstr.3, 06466 Gatersleben, Germany. ${ }^{2}$ KWS LOCHOW GmbH, Ferdinandvon-Lochow-Str.5, 29303 Bergen, Germany. ${ }^{3}$ Nordsaat Saatzucht GmbH, Böhnshauser Straße 1, 38895 Langenstein, Germany.

\section{Authors' contributions}

SW carried out the molecular genetic analysis, sequence alignment and linkage mapping, and participated in the design of experiments and the drafting of the marker part of the manuscript. CP designed the PCR primers, while RK and VTH performed the glasshouse drought tolerance assessments, measured starch content and isolated RNA. AB, VK and LK provided genetic material and conducted the field-based drought screening. MSR monitored the marker study and co-edited the part of manuscript, along with UW who conceived the study. NS coordinated the work of the GABI-GRAIN consortium, contributed to the development of concepts, conducted gene expression analysis and critically revised the manuscript. All the authors have read and approved the final manuscript.

Received: 9 June 2010 Accepted: 4 January 2011

Published: 4 January 2011

\section{References}

1. Pennisi E: Plant genetics. The blue revolution, drop by drop, gene by gene. Science 2008, 320:171-173.

2. Chen G, Krugman T, Fahima T, Chen K, Hu Y, Röder M, Nevo E, Korol A: Chromosomal regions controlling seedling drought resistance in Israeli wild barley, Hordeum spontaneum C. Koch. Genet Resour Crop Evol 2010, 57:85-99. 
3. Diab AA, Teulat-Merah B, This D, Ozturk NZ, Benscher D, Sorrells ME: Identification of drought-inducible genes and differentially expressed sequence tags in barley. Theor App/ Genet 2004, 109:1417-1425.

4. Teulat B, Merah O, Sirault X, Borries C, Waugh R, This D: QTLs for grain carbon isotope discrimination in field-grown barley. Theor Appl Genet 2002, 106:118-126

5. Tondelli A, Francia E, Barabaschi D, Aprile A, Skinner JS, Stockinger EJ, Stanca AM, Pecchioni N: Mapping regulatory genes as candidates for cold and drought stress tolerance in barley. Theor Appl Genet 2006, 112:445-454.

6. von Korff M, Grando S, Del Greco A, This D, Baum M, Ceccarelli S: Quantitative trait loci associated with adaptation to Mediterranean dryland conditions in barley. Theor Appl Genet 2008, 117:653-669.

7. Rostoks N, Mudie S, Cardle L, Russell J, Ramsay L, Booth A, Svensson JT, Wanamaker SI, Walia H, Rodriguez EM, et al: Genome-wide SNP discovery and linkage analysis in barley based on genes responsive to abiotic stress. Mol Genet Genomics 2005, 274:515-527.

8. Close TJ, Bhat PR, Lonardi S, Wu Y, Rostoks N, Ramsay L, Druka A, Stein N, Svensson JT, Wanamaker $S$, et al: Development and implementation of high-throughput SNP genotyping in barley. BMC Genomics 2009, 10:582.

9. Sato K, Nankaku N, Takeda K: A high-density transcript linkage map of barley derived from a single population. Heredity 2009, 103:110-117.

10. Stein N, Prasad M, Scholz U, Thiel T, Zhang H, Wolf M, Kota R, Varshney RK, Perovic D, Grosse I, Graner A: A 1,000-loci transcript map of the barley genome: new anchoring points for integrative grass genomics. Theor Appl Genet 2007, 114:823-839.

11. Feuillet $C$, Langridge $P$, Waugh $R$ : Cereal breeding takes a walk on the wild side. Trends Genet 2008, 24:24-32.

12. Schmalenbach I, Pillen K: Detection and verification of malting quality QTLs using wild barley introgression lines. Theor App/ Genet 2009, 118:1411-1427.

13. von Korff M, Wang H, Leon J, Pillen K: AB-QTL analysis in spring barley: II. Detection of favourable exotic alleles for agronomic traits introgressed from wild barley (H. vulgare ssp. spontaneum). Theor Appl Genet 2006, 112:1221-1231.

14. Backes G, Madsen LH, Jaiser H, Stougaard J, Herz M, Mohler V, Jahoor A: Localisation of genes for resistance against Blumeria graminis f.sp. hordei and Puccinia graminis in a cross between a barley cultivar and a wild barley (Hordeum vulgare ssp. spontaneum) line. Theor Appl Genet 2003, 106:353-362.

15. von Korff M, Wang $H$, Leon J, Pillen K: AB-QTL analysis in spring barley. I. Detection of resistance genes against powdery mildew, leaf rust and scald introgressed from wild barley. Theor Appl Genet 2005, 111:583-590.

16. Shavrukov Y, Gupta NK, Miyazaki J, Baho MN, Chalmers KJ, Tester M Langridge P, Collins NC: HvNax3-a locus controlling shoot sodium exclusion derived from wild barley (Hordeum vulgare ssp. spontaneum). Funct Integr Genomics 2010, 10:277-291.

17. Guo P, Baum M, Grando S, Ceccarelli S, Bai G, Li R, von Korff M, Varshney RK, Graner A, Valkoun J: Differentially expressed genes between drought-tolerant and drought-sensitive barley genotypes in response to drought stress during the reproductive stage. J Exp Bot 2009, 60:3531-3544

18. Hubner S, Hoffken M, Oren E, Haseneyer G, Stein N, Graner A, Schmid K, Fridman E: Strong correlation of wild barley (Hordeum spontaneum) population structure with temperature and precipitation variation. $\mathrm{Mol}$ Ecol 2009, 18:1523-1536.

19. James VA, Neibaur I, Altpeter F: Stress inducible expression of the DREB1A transcription factor from xeric, Hordeum spontaneum L. in turf and forage grass (Paspalum notatum Flugge) enhances abiotic stress tolerance. Transgenic Res 2008, 17:93-104.

20. Pietsch C, Sreenivasulu N, Wobus U, Röder MS: Linkage mapping of putative regulator genes of barley grain development characterized by expression profiling. BMC Plant Biol 2009, 9:4

21. Li JZ, Huang XQ, Heinrichs F, Ganal MW, Röder MS: Analysis of QTLs for yield components, agronomic traits, and disease resistance in an advanced backcross population of spring barley. Genome 2006, 49:454-466.

22. von Korff M, Wang H, Leon J, Pillen K: Development of candidate introgression lines using an exotic barley accession (Hordeum vulgare ssp. spontaneum) as donor. Theor Appl Genet 2004, 109:1736-1745.

23. Marcel TC, Varshney RK, Barbieri M, Jafary H, de Kock MJ, Graner A, Niks RE: A high-density consensus map of barley to compare the distribution of
QTLs for partial resistance to Puccinia hordei and of defence gene homologues. Theor Appl Genet 2007, 114:487-500.

24. Varshney RK, Marcel TC, Ramsay L, Russell J, Röder MS, Stein N, Waugh R, Langridge P, Niks RE, Graner A: A high density barley microsatellite consensus map with 775 SSR loci. Theor App/ Genet 2007, 114:1091-1103.

25. Vlad F, Rubio S, Rodrigues A, Sirichandra C, Belin C, Robert N, Leung J, Rodriguez $\mathrm{PL}$, Lauriere $\mathrm{C}$, Merlot $\mathrm{S}$ : Protein phosphatases $2 \mathrm{C}$ regulate the activation of the Snf1-related kinase OST1 by abscisic acid in Arabidopsis. Plant Cell 2009, 21:3170-3184

26. Fujii H, Chinnusamy V, Rodrigues A, Rubio S, Antoni R, Park SY, Cutler SR, Sheen J, Rodriguez PL, Zhu JK: In vitro reconstitution of an abscisic acid signalling pathway. Nature 2009, 462:660-664.

27. Sreenivasulu N, Sopory SK, Kavi Kishor PB: Deciphering the regulatory mechanisms of abiotic stress tolerance in plants by genomic approaches. Gene 2007, 388:1-13

28. Miller G, Mittler R: Could heat shock transcription factors function as hydrogen peroxide sensors in plants? Ann Bot 2006, 98:279-288.

29. Pelger $\mathrm{S}$, Säll T, Bengtsson BO: Evolution of hordein gene organization in three Hordeurn species. Hereditas 1993, 119:219-231.

30. Radchuk W, Sreenivasulu N, Radchuk RI, Wobus U, Weschke W: The methylation cycle and its possible functions in barley endosperm development. Plant Mol Biol 2005, 59:289-307.

31. Sorensen MB: Methylation of B-hordein genes in barley endosperm is inversely correlated with gene activity and affected by the regulatory gene Lys3. Proc Natl Acad Sci USA 1992, 89:4119-4123.

32. Haseneyer G, Stracke S, Piepho HP, Sauer S, Geiger HH, Graner A: DNA polymorphisms and haplotype patterns of transcription factors involved in barley endosperm development are associated with key agronomic traits. BMC Plant Biol 2010, 10:5.

33. Sreenivasulu N, Borisjuk L, Junker B, Mock HP, Rolletschek H, Seiffert U, Weschke W, Wobus U: Barley grain development: towards an integrative view. International Review of Cell and Molecular Biology 2010, 281:49-89.

34. Sreenivasulu N, Radchuk V, Strickert M, Miersch O, Weschke W, Wobus U: Gene expression patterns reveal tissue-specific signaling networks controlling programmed cell death and ABA- regulated maturation in developing barley seeds. Plant J 2006, 47:310-327.

35. Sreenivasulu N, Usadel B, Winter A, Radchuk V, Scholz U, Stein N, Weschke W, Strickert M, Close TJ, Stitt M, et al: Barley grain maturation and germination: metabolic pathway and regulatory network commonalities and differences highlighted by new MapMan/PageMan profiling tools. Plant Physiol 2008, 146:1738-1758.

36. Sulpice R, Pyl ET, Ishihara H, Trenkamp S, Steinfath M, Witucka-Wall H, Gibon Y, Usadel B, Poree F, Piques MC, et al: Starch as a major integrator in the regulation of plant growth. Proc Natl Acad Sci USA 2009, 106:10348-10353.

37. Thévenot $C$, Simond-Cote $E$, Reyss A, Manicacci D, Trouverie J, Le Guilloux M, Ginhoux V, Sidicina F, Prioul JL: QTLs for enzyme activities and soluble carbohydrates involved in starch accumulation during grain filling in maize. J Exp Bot 2005, 56:945-958.

38. Radchuk W, Borisjuk L, Sreenivasulu N, Merx K, Mock HP, Rolletschek H, Wobus U, Weschke W: Spatiotemporal profiling of starch biosynthesis and degradation in the developing barley grain. Plant Physiol 2009, 150:190-204

39. Pan A, Hayes PM, Chen F, Chen THH, Blake T, Wright S, Karsai I, Bedö Z: Genetic analysis of the components of winterhardiness in barley (Hordeum vulgare L.). Theor App/ Genet 1994, 89:900-910.

40. Teulat B, Zoumarou-Wallis N, Rotter B, Ben Salem M, Bahri H, This D: QTL for relative water content in field-grown barley and their stability across Mediterranean environments. Theor App/ Genet 2003, 108:181-188.

41. Chen G, Komatsuda T, Pourkheirandish M, Sameri M, Sato K, Krugman T, Fahima $T$, Korol AB, Nevo E: Mapping of the eibi1 gene responsible for the drought hypersensitive cuticle in wild barley (Hordeum spontaneum). Breeding Science 2009, 59:21-26.

42. Chen G, Pourkheirandish M, Sameri M, Wang N, Nair S, Shi Y, Li C, Nevo E, Komatsuda T: Genetic targeting of candidate genes for drought sensitive gene eibi1 of wild barley (Hordeum spontaneum). Breeding Science 2009, 59:637-644.

43. Kleinhofs A, Kilian A, Saghai Maroof MA, Biyashev RM, Hayes P, Chen FQ, Lapitan N, Fenwick A, Blake TK, Kanazin V, et al: A molecular, isozyme and morphological map of the barley (Hordeum vulgare) genome. Theor Appl Genet 1993, 86:705-712. 
44. Costa JM, Corey A, Hayes PM, Jobet C, Kleinhofs A, Kopisch-Obusch A, Kramer SF, Kudrna D, Li M, Riera-Lizarazu O, et al: Molecular mapping of the Oregon Wolfe Barleys: a phenotypically polymorphic doubledhaploid population. Theor Appl Genet 2001, 103:415-424.

45. Plaschke J, Ganal MW, Röder MS: Detection of genetic diversity in closely related bread wheat using microsatellite markers. Theor Appl Genet 1995, 91:1001-1007.

46. Rolletschek H, Koch K, Wobus U, Borisjuk L: Positional cues for the starch/ lipid balance in maize kernels and resource partitioning to the embryo. Plant J 2005, 42:69-83.

47. Merrill A, Watt BK: Energy value of foods, basis and derivation. United States Department of Agriculture Handbook 74 USDA, Washington, DC; 1973.

48. Steiger JH: Tests for comparing elements of a correlation matrix. Psychological Bulletin 1980, 87:245-251.

49. Huang XQ, Röder MS: Development of SNP assays for genotyping the puroindoline $\mathrm{b}$ gene for grain hardness in wheat using pyrosequencing. J Agric Food Chem 2005, 53:2070-2075.

50. Van Ooijen JW: JoinMap 4, Software for the calculation of genetic linkage maps in experimental populations Wageningen, Netherlands: Kyazma B. V; 2006.

51. Abebe T, Melmaiee K, Berg V, Wise RP: Drought response in the spikes of barley: gene expression in the lemma, palea, awn, and seed. Funct Integr Genomics 2010, 10:191-205.

52. Sreenivasulu N, Altschmied L, Radchuk V, Gubatz S, Wobus U, Weschke W: Transcript profiles and deduced changes of metabolic pathways in maternal and filial tissues of developing barley grains. Plant J 2004, 37:539-553.

53. Lohse M, Nunes-Nesi A, Krüger P, Nagel A, Hannemann J, Giorgi FM, Childs L, Osorio S, Walther D, Selbig J, et al: Robin: An intuitive wizard application for R-based expression microarray quality assessment and analysis. Plant Physiol 2010, 153:642-651.

54. Sturn A, Quackenbush J, Trajanoski Z: Genesis: cluster analysis of microarray data. Bioinformatics 2002, 18:207-208.

doi:10.1186/1471-2229-11-1

Cite this article as: Worch et al:: Haplotyping, linkage mapping and expression analysis of barley genes regulated by terminal drought stress influencing seed quality. BMC Plant Biology 2011 11:1.

\section{Submit your next manuscript to BioMed Central and take full advantage of:}

- Convenient online submission

- Thorough peer review

- No space constraints or color figure charges

- Immediate publication on acceptance

- Inclusion in PubMed, CAS, Scopus and Google Scholar

- Research which is freely available for redistribution

Submit your manuscript at www.biomedcentral.com/submit
Biomed Central 